\title{
TAKING A STAND: STANCE STRATEGIES IN L1 SERBIAN ENGLISH LEARNERS' EXPOSITORY ESSAYS
}

\author{
Marta Veličković ${ }^{1}$, Jelena Danilović Jeremić ${ }^{2}$ \\ ${ }^{1}$ Faculty of Philosophy, University of Niš, Serbia \\ E-mail: marta.velickovic@ filfak.ni.ac.rs \\ ${ }^{2}$ Faculty of Philology and Arts, University of Kragujevac, Serbia \\ E-mail: jelena.jeremic@filum.kg.ac.rs
}

\begin{abstract}
An important part of undergraduate essay writing is the argumentative/persuasive essay genre, which has been described as one of the keys to academic success in higher education (Chandrasegaran and Kong, 2006). It requires not only grammatical fluency and appropriate cohesion, but also that the author be able to take a stand on a particular issue. In an attempt to understand what strategies Serbian L1 English learners at the tertiary level use to take a stand, we analyzed a corpus of their expository (argumentative and opinion) essays. The essays were analyzed and coded for various linguistic structures used to convey taking a stand. These include nouns which are preceded by a sentence initial deictic This as a structure which encapsulates previous propositions, reported speech used to assign a stance to and take a stand on the reported speaker and the event, the passive voice, demonstrative pronouns, and the like. The quantitative analysis of this material was carried out with the aim of presenting our findings in the light of possible implications for teaching expository/persuasive writing at the tertiary level to NNS of English, in an attempt to bridge the intercultural gap that any NNS faces when forced to express their opinions in a language other than their own.
\end{abstract}

Key words: stance, EFL writing, university-level NNS, teaching expository writing in an academic setting

\section{INTRODUCTION}

Learning to write at the undergraduate level is a challenging task for most Serbian L1 English learners. On the one hand, writing is a skill that requires grammatical fluency and appropriate cohesion (Chandrasegaran and Kong, 2006; Min et al., 2019). On the other, the rules of English L2 academic writing and those of Serbian academic writing do not overlap to a great extent. In their 2007 paper, Filipović et al. discussed education policy and planning as it pertained to all the languages studies in Serbian primary and secondary schools, and outlined some of their teaching methods. It was their conclusion that Serbian as the official L1 is still being taught in the tradition of structuralism, with a strong focus on 'deductive grammar rules', and not much focus being devoted to the 'sociolinguistic and pragmatic aspects of language use'. An outcome of implementing such a method on a national level is that prospective tertiary level students test low on communicative competence including writing for special purposes, writing term papers, delivering presentations and public speeches. This was indicated by some preliminary international 
PISA (Programme for International Student Assessment) testing results obtained from a population of students from Serbia in 2003. Therefore, constructing a persuasive argument is a challenge in the tertiary academic setting. To this we add the intercultural gap that all NNSs face when they are asked to express their opinions in a language other than their own (Hyland, 2012), taking into consideration not only the rules of English L2 writing, but also the specific dictates of Anglophone academic discourse.

At the tertiary level of study of the English language in Serbia, students are regularly required to express their opinions in writing as part of their obligatory coursework. More often than not, assessment of their work is based primarily on their writing performance (see Chandrasegaran, 2008; Lee and Deakin, 2016). Their writing does not infrequently take the form of argumentative or opinion essays, in which L2 learners are asked to express and support their opinions and assessments. The expression of the writer's personal feelings/opinions, attitudes, assessments and value judgments by means of linguistic resources is known as stance. Considering the fact that speaker positionality is built into the very act of communication, the study of stance is inevitably required to improve (English) L2 writing skills. The case for such study is made even more strong considering that English is for all intents and purposes now considered the lingua franca of the academic world, and that the need to master these necessary L2 writing skills surpasses the boundaries of scientific fields or 'hard' and 'soft' disciplines, and even formal and informal discourse situations (Chandrasegaran, 2008). Some of the most influential work done on analyzing stance is based on Hyland's (2005) model of academic interaction. In it, the distinction is not drawn between whether an author of an academic paper is a NS or NNS, but is drawn in relation to the author's level of knowledge of academic norms. The inference is that the lack of publication of academic writing is the result not so much of inappropriate language use, but underdeveloped argumentation, lack of an effective authorial voice, lack of interaction with the readers, or in general, not adhering to the norms of academic writing of the environment in which the author aims to publish (see Swales, 1990).

A quantitative and qualitative analysis of stance requires adopting an operationalizable definition of it. Numerous accounts of stance have been provided over the years. Biber and Finegan (1989) termed stance as the 'lexical and grammatical' way of expressing the attitudes, the judgments, or even feelings and level of commitment regarding a proposition. Charles (2003) connected taking a particular stance as a representation of one's status as a knowledgeable member of a particular field. Hyland's (2005) comprehensive definition of stance takes into consideration the interaction between the author and the reader, and emphasizes authorial stance, which can also be referred to as 'writer identity', 'authorial voice' or 'authorial presence'. It includes numerous dimensions of stance, including personal/impersonal, present/absent, overt/covert, explicit/implicit, subjective/objective, involved/detached, or concrete/abstract. Englebretson (2007) maintained that the term 'stance' is sometimes used to denote what some scholars refer to as subjectivity, while other language researchers prefer the term 'evaluation'. Baratta (2009) further claimed that by giving this personal stamp, a (student) writer reveals him/herself as part of a personal identity seen within an otherwise academic essay. Hyland (2012) recently also stressed that establishing a connection with the audience, among other things by indicating our attitude to the content being put forward, is an important aspect of formal academic writing.

In this study we opted for the definition of stance-taking as of taking up a position with respect to the form or the content of one's utterance, in accordance with Jaffe's views on the issue (2009). The aim of the paper was to analyze stance-taking patterns in 
English L2 academic writing for the purpose of providing information relevant for the L2 teaching process, with a view to improving the English L2 writers' further efforts.

\section{THEORETICAL BACKGROUND}

The primary focus of research carried out to date was how the various lexico-syntactic features of linguistic structures interact with thematic content to express discourse stance; how they differ as a function of text type; how they depend on the age or literacy level of the writer, and also how they differ cross-linguistically, reflecting different rhetorical options favored by the speakers or writers of different languages, as outlined in Berman (2004). To sum up, research on stance involves not only developing an understanding of the full social and pragmatic nature of language, but also evaluating how it is used by actual speakers or writers to act and interact in the real world.

Based on the selected and sufficiently exhaustive parameters of development (referring to the age and level of education of the writers), genre (the type of essay being written, in particular whether it is a narrative or expository essay), modality (written or spoken) and finally the target language, Berman (ibid.) determined the emergence of certain shared trends across the sample. The devices for distancing of the speaker-writer from the contents of the text change both in terms of amount and cross-linguistically.

There is no shortage of the variety of lexico-grammatical resources that are used to convey stance which have been studied to date. Seminal research on the identification of stance styles in English is that of Biber and Finegan (1989). To provide an exhaustive and valid overview of overt markers of affect and evidentiality in English, they analyzed 500 spoken and written samples of language use which spanned 24 different genres. Their analysis yielded 12 stance categories, and a total of 6 stance styles, including: 'emphatic expression of affect', 'faceless stance', 'interactional evidentiality', 'expository expression of doubt', 'predictive persuasion', 'oral controversial persuasion'. They reached two significant conclusions: one, that the 'faceless stance' style was the dominant style in their analyzed sample, which indicates that L1 English writing seems to be marked by an absence of direct expression of affect or evidentiality. To quote:

"This overall pattern indicates that such expression of stance (affective or evidential) is a 'marked' choice in English, and that the prevailing norm is to leave stance lexically and grammatically unmarked, thus putting the burden on addressees to infer a speaker's stance" (1989, p. 108).

The second was that both lexical and grammatical features need to be taken into consideration in any analysis of stance, as one or the other type of feature may emerge as dominant in a particular piece of writing, at the expense of the other feature. To reach these conclusions, Biber and Finegan analyzed adverbial, adjectival, verbal and modal stance markers. These included affect markers (adverbs, verbs, and adjectives), certainty adverbs, certainty verbs, certainty adjectives, doubt adverbs, doubt verbs, doubt adjectives, hedges, emphatics, possibility modals, necessity modals, and predictive modals. Further lexicogrammatical stance features that were studied included hedges and boosters (Hyland, 1998; 1999; 2000) and the passive voice (Baratta, 2009). Min et al. (2019) paid special attention to hedges in Korean EFL learners' argumentative writing. In their study they distinguished between the formal quality and the content quality of this type of writing. Their conclusion was that the same stance devices used by the same student authors did not predict both types of quality at the same time. 
In addition to essays written as part of the curriculum requirements, previous research on stance-taking and stance support in academic discourse included theses and scholarly articles. Such is the research carried out by Blagojevic (2009), Charles (2007), and Silver (2003), to name but a few. Furthermore, formal settings were not the only ones to be considered as Chandrasegaran (2008) for example, compared the means of presenting arguments in both a formal and informal discourse setting. Different languages were also looked at in addition to English, either individually or in comparison to other languages. It is worth pointing out that Blagojević (2009) studied writing samples from Serbian and English authors, in an attempt to reveal their attitudes towards the content they are reporting in their academic research articles. She determined that the same linguistic forms were used in both languages. Van Hell et al. (2005) evaluated stance-taking and support in writing in only one language, Dutch, but also based their research on a variety of parameters including genre and modality. Ragnarsdottir and Stromqvist (2005) evaluated discourse stance in Icelandic and Swedish, while Chang (2009) evaluated stance uses in Mandarin LE. Lee and Deakin (2016) cited, as did Min et al. (2019), frequent occurrences of interactional metadiscourse, or how writers engage with readers (Hyland, 2005), in student academic writing, irrespective of the students' L1, the number of years they spent studying English, or even the level of success with which they completed the writing task. Their results recorded that all of the participants marked their stance in their writing.

The question of NS vs. NNS stance has also figured as a topic of research. Some of the questions that were raised in studies that compared NS (in these cases English language speakers) and NNS stance revolved around the following two points:

1. whether the speakers' different L1s may evoke English as a Foreign Language or EFL-specific patterns of stance-taking and

2. in EFL communication the speakers are focused on the expression of ideational meaning, including the handling of miscommunication. The linguistic construction of a particular speaker persona or speaker identity in their discourse and of acts of 'socializing' with their interlocutor, i.e. interpersonal meaning-making, appears comparatively less relevant (Baumgarten and House, 2010).

In their recent study, Baumgarten and House (ibid.) analyzed whether $I+$ verb collocations (e.g. I think, I hope, I guess) are the most dominant expressions of stance in English L1 and English L2 communication. They found evidence of partially overlapping diversification:

1. L2 speakers use $I$ think $^{I}$ when speaker stance towards the proposition is already implicated, so the collocation presents an additional, overt marker of the speaker's subjective perspective, and

2. the expression of subjectivity is seen as a potential trouble spot by the participants in the ELF conversations.

The analysis presented in this paper includes the following: (1) an overview of existing research to compile a list of grammatical/lexical markers of stance; (2) analysis of the selected sample of student writing to determine the frequency of occurrences of each individual marker in the sample; (3) a potential interpretation of the results identified in the sample and the ensuing implications.

\footnotetext{
${ }^{1}$ For more details on using I think as a stance-taking and stance-indicating means, see Kärkkäinen (2003).
} 


\section{THE METHOD}

In this particular research, we wanted to gain insight into the extent to which a group of college students from a NNS background (L1 Serbian) is capable of engaging in stance assertion in written form. This in turn would have implications for the teaching of expository/persuasive writing at the tertiary level, as the gathered data would enable us to see what strategies are evident in the students' writing and how they are relevant for university essay writing, which is in line with Chandrasegaran and Kong's beliefs (2006). Any changes that could be made to the students' style of writing in this sense would be a suitable preparation for their future academic career, as the adequate positioning of the speaker's self in the discourse is seen as a central task to be mastered if one is to be admitted to any professional or non-professional discourse community or other communities of practice, as indicated by Baumgarten and House (2010).

\subsection{The research material}

To carry out the research, we compiled a corpus of expository texts written with a persuasive purpose by the seniors at the English Department of the Faculty of Philosophy, University of Niš, which represents a homogenous L1 group. The course that the participants were enrolled in was a senior-year academic writing course, a part of a more general Contemporary English Language course, where the focus was on developing the students' grammar and vocabulary skills, overall level of L2 proficiency, developing their skills of organizing and presenting information clearly, achieving coherence, and to a small extent, the use of sources. The level of proficiency of the students taking part in the essay writing course was assessed to be advanced based on the level of academic study.

Special care was taken in terms of genre, as differences in stance-taking and support based upon it (written narrative vs. expository texts) were found by Reilly et al. (2005). We intentionally focused on seniors as the most proficient body of students at the department, who as Lee and Deakin (2016, p. 23) state, represent a far more appropriate target group than authors of published research articles. Moreover, the expository/argumentative essay genre was also purposefully selected, as it is considered the key to academic success in higher education (Chandrasegaran and Kang, 2006).

The students were provided with three possible topics for their essays, of which they selected one, with the addition that the topics had previously been discussed in class. Essays were written on topics including advertising, the relationship between technology and books, and relying on other people's opinions when making important decisions. The approximate text length of the essays was 300 words, and the assignment was to be completed in $75 \mathrm{~min}$, which is the standard allotted time at this particular department. Our corpus consisted of 50 texts, numbering approximately 17,500 words. In order to answer the question of which linguistic resources were most commonly employed by our students, the essays were analyzed and coded by two ESL writing teachers who provided the total number of interactional metadiscourse means within the essays. 
The essays were coded for the following linguistic resources, based on the relevant work of other authors:

1. sentence initial deictic this/that (Charles, 2003) and demonstratives

We have commercials which promote different kind of courses, schools and universities, which is good. This will probably have a positive effect and a result on the young people. This type of advertising says to them that learning, reading and being a good student ${ }^{2}$....

2. the passive (Baratta, 2009; van Hell et al., 2005) as a subtle way for writers to reveal themselves

We live in the world which is globally connected by mass media like TV, newspapers, etc. Although it is widely accepted that advertising...

3. pronouns (Berman, 2004; Grigoriev and Sokolova, 2019)

the very personal $(I)$ and the impersonal, generic (we, you)

4. reported speech (Niemelä, 2010; Vincent and Perrin, 1999) in its appreciative, support authority functions

While many consider advertisments harmless, and even beneficial to young person's lives, the opponents point out their disasterous effects.

5. nouns followed by that and a complement clause (Charles, 2007; Jiang, 2017; Man and Chau, 2019)

...the fact that they are omnipotent.

6. adverbials (Silver, 2003) as attitudinal markers (Kärkkäinen, 2003)

maybe, probably, apparently, etc.

7. and impersonal structures in general

it is widely agreed, there are, etc.

\section{RESULTS AND DISCUSSION}

The results indicated the following, listed in a descending order in terms of frequency of occurrence and presented in a graphic form (Fig. 1.):

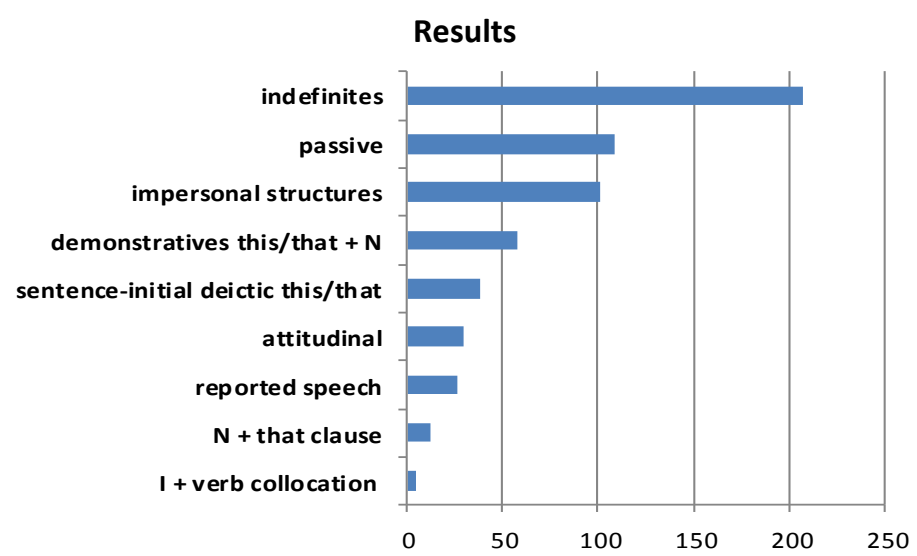

Fig. 1 Frequency of occurrence of the targeted linguistic resources in the corpus

\footnotetext{
${ }^{2}$ All of the examples given in this paper have been extracted from the reviewed student essays.
} 
The results have indicated that the students primarily focused on distance and objectivity in their writing, as evidenced by the frequent use of indefinites/impersonal structures especially in combination with the passive voice. There were very few 'personal' comments in the form of $I+v e r b$ collocations or attitudinal markers. In addition, the linguistic resources used in the texts were not directly related to the writer's skill level, which means that a higher level of proficiency in English was neither an indicator of a greater variety of linguistic resources used to indicate stance, nor of their greater number (compare Min et al., 2019). Thus, the stance that is expressed seems not to be dependent on foreign language knowledge, which means there are grounds to conclude that we could influence Serbian EFL learners' choice of used linguistic resources. In addition, our results suggest that the studied group of English L2 speakers consider the expression of stance as personal input of secondary importance in this form of communication. Our students seem to tend not to want to disrupt the overall objective tone of this type of academic essay and generally do not include their 'personal stamp' in it.

A question which imposes itself is how much of this is a reflection of what the students had been taught, as it is a well-known fact that certain approaches to teaching writing, such as the genre approach (Gee in Luchini, 2002), emphasize the use of 'scaffolding' or a framework, the model upon which learners base their texts and thus mimic other people's writings (Nunan, 1989; Harmer, 2004). Since this particular group of students has explicitly been taught that academic writing in English is formal and impersonal, and that they have, to our knowledge, received vague formal instruction in terms of writing standards in Serbian during their primary/secondary school education, it seems plausible that their production is the result primarily of modeling. As Reilly et al. (2005) pointed out in the introduction to their paper, the use of impersonal pronouns, passive constructions, and attitudinal markers in the written narrative and expository texts of English-speaking children, adolescents, and adults seems to be on the increase. They pointed out that this increase in the development of a more distanced, impersonal stance is now characteristic of the expository genre.

In their research, Biber and Finegan (1989) also found a prevalence of what they referred to as the 'faceless stance', or the absence of all stance features, in as many as $65 \%$ of the analyzed material. Their interpretations of the results make reference to several important features of writing in an Anglophone setting: that spoken language expresses more affect than written language, and that personal letters, including love letters, or personal interaction such as conversations between close friends, is the setting where direct markers of stance should be sought, and not in examples of academic writing. Furthermore, expository genres are considered formal, and the focus in this type of writing is on the content or proposition being conveyed, rather than on the stance of the author. To quote:

"the specialized styles are found in informational, often written, texts, which place strong emphasis on an exact presentation of information and thus require a more precise marking of evidential stance. This does not result in a more frequent marking of stance in these latter texts: rather, it results in a more specific marking of certainty or doubt (as opposed to a general emphatic indication of stance), using adjectival forms (which are more integrative)." (1989, p. 117)

And yet, the situation may not be that clear cut. Our empirical findings echo what Hyland (2012, p. 137) previously stated, and that is that our participants have perceived, or learned, that "academic writing in English is impersonal and faceless", even though his 
own research findings have indicated that this is not entire the case. He goes so far as to say that L2 writers who do this are "relinquishing their personal authority by anonymizing their writing" (ibid, p. 145), and this is not their only recourse. As Kärkkäinen (2003) indicated, epistemic modality can be both personalized and impersonalized, which means that any group of L2 writers has a choice regarding how they wish to convey certain propositions. To quote:

"In my database, the most common type of occurrence of epistemic modality was a cognitive or perception or utterance verb (cf. Givón 1993 for P-C-U verbs) with a firstperson subject, with no complementizer that following. Holmes (1982: 27, 1988: 43) proposes the following grammatical patterns expressing epistemic modality that may include a lexical verb:

a. I (think/believe/guess etc.) that $\mathrm{p}$

b. It (seems/appears) to me that $p$

- personalized

c. It (seems/appears) that $\mathrm{p}$

- personalized

d. NP (argues/claims etc.) that $\mathrm{p}$ (NP is animate $+3 \mathrm{rd}$ person) $\quad-$ depersonalized

We can see in Table 2 that group (a) is by far the most frequent group of epistemic markers in the American English spoken discourse represented in my database. This group consists of personalized markers that clearly make reference to the speaker's subjective stance, such as I think, I guess, I know, I feel (like), I found etc." (2003, p. 38, original emphasis)

Furthermore, Min et al. (2019) in their study of Korean L1 English L2 writing noted, with a high level of statistical significance, that "advanced Korean EFL learners relied most heavily on the use of stance verbs in making their points" (ibid, p. 13), which included examples such as (ibid, p. 12; original emphasis):

It is proven that secondhand smoking is dangerous.

I guess they don't mind if I smoke.

For example, when I go to pc-rooms to use computers, I always smell smoke and it makes me feel awful.

Let us all hope to see a change in the law regarding public smoking.

However, such argument cannot be accepted as long as the right of a group of people requires sacrifice of others.

The doctors insisted that I should stop smoking.

On the other hand, unlike in the case of the aforementioned examples, the 'reluctance' to present themselves as an authorial identity identified among our sample of participants also echoes the results obtained by Lee and Deakin (2016), who analyzed the argumentative essays of advanced L1 Chinese EFLs, where according to the authors, selfmentions were 'the least frequently used category'. They also indicated the importance of intersubjectivity as a prerequisite for an effective rapport with the audience, and thus a more successful essay. To quote:

"The greater inclusion of particularly hedges in successful essays appears to lead to them being considered ultimately more persuasive than less-successful essays, as such devices are highly valued in Anglophone academic cultures [...] However, unlike L1 writers, the findings also reveal the overwhelming resistance of both ESL groups to demarcate their authorial presence within their texts. This reluctance may indicate Chinese ESL students' discomfort with taking on a stronger writer identity, and instead preferring to maintain an impersonal and detached writing style that may be considered safe and familiar." (ibid, p. 31) 
Similar results were found in the writing of advanced L1 English L2 German writers, who opted for more subtle expressions of their opinions in their L2 writing (RyshinaPankova, 2011). Ryshina-Pankova states that in persuasive/argumentative writing the tendency is to back away from explicit markers of personal opinion, to engage the reader by anticipating their responses, and thus 'encourage' the audience to be persuaded by the authors' arguments (ibid, p. 244). This translates into an increased number of reader references, rather than references to the author. She even cited a study (Coffin and Hewings, 2004) in which a comparison was made between beginner and final year undergraduate students. Following an analysis of their work, a trend was noted in which authorial stance conveyed by the use of pronouns over time was slowly but surely replaced by an avoidance of such explicit strategies, a process which is echoed in Ryshina-Pankova's own study.

Analyzing a corpus of personal experience narratives and expository discussions, Hell et al. (2005) also found impersonal pronouns to be the option of choice for Dutch speakers. Similar results were found by Reilly et al. (2005) during the course of a cross-linguistic study of English L1 writing. Based on these results, we might be tempted to say that it is precisely the ongoing process of the downplaying of the interpersonal while foregrounding complex content, which is characteristic of academic discourse, that creates the need to further analyze stance.

Thus, overall, it would seem that our students are actually following the trends of other L2 English language speakers. Compared to their writing samples, what we could conclude to be lacking is a variety in the range of linguistic devices used in conveying this particular impersonal style. As English teachers working in an academic environment, we could make use of this state of affairs to instruct and help our students use a wider, broader range of devices, thus aiding them to further develop their linguistic skills, but also increase their chances of writing more successful essays which the audience would be more receptive to, and thus the possibility of them publishing their work.

\section{CONCLUDING REMARKS}

As indicated, even the definition of the concept of stance can prove a challenge in the academic setting, since some, such as Englebretson (2007), maintain that the term stance is sometimes used to denote what some scholars refer to as subjectivity, while other language researchers prefer the term evaluation over that of stance. To properly understand and define stance, it is necessary to conceive of language in terms of the functions for which it is used, in conjunction with the contexts within which it occurs. To clarify, stance is the expression of the writer's personal feelings/opinions, attitudes, assessments and value judgments by means of linguistic resources. According to Charles (2003), in a particular piece of writing, the writer takes a particular stance as a knowledgeable member of the field. Baratta (2009) further claimed that by giving this personal stamp, a writer, or in our case a student, reveals him/herself as part of a personal identity seen within an otherwise academic essay. It is possible to further study how this personal voice contributes to an overall objective tone in academic writing (ibid.). Within the scope of this study we attempted to identify and outline how a group of L1 Serbian L2 English speakers use stance-taking or stance-indicating means on a sample of essays written on topics including advertising, the relationship between technology and books, and relying on other people's opinions when making important decisions, in order to shed some light on their current 
abilities or willingness to overtly express stance in their L2 writing. Overall, it was determined that they assumed a more aloof, impersonal style when writing in an academic setting.

With the exception of the findings of Blagojevic (2009), there is an unfortunate lack of additional research into the matter of stance in L1 Serbian L2 English academic writing. Therefore, we cannot compare our results with any other obtained at this level, which at the same time provides ample space for future investigations. To gain more conclusive evidence about the factors that may affect Serbian EFL learners' use of stance-taking devices, further research on this topic could include a comparative study of essays written by the same students in both their native and foreign language so that a parallel could be drawn between the two modes of expression and the similarities/differences between L1 and L2 writing styles might be explored. In addition, a further line of research might involve comparing the way our students use stance in their writing, but in different essay types, contrasting for instance the usage of the aforementioned linguistic resources in expository vs. persuasive essays, primarily opinion essays, or the use of these resources in narrative essays.

One of the pedagogical implications that can be drawn from these research results is that more direct instruction on interactional metadiscourse is needed (as proposed by Lee and Deakin, 2016, and further studied by Min et al., 2019), so that writing could be an interactional, dialogical activity, one that engages the reader. Min et al. (2019) stated that it not always possible to find evidence of either conviction or uncertainty in L2 writing, as it is in NS writing, but also determined a confusing underuse or overuse of stance adjectives which they ascribed either to the participants' level of L2 proficiency or the discourse community in which the text was written. If performance is affected by level of proficiency, this is an aspect that can directly be influenced in the L2 classroom.

The study also has some limitations that need to be addressed. For one, the essays were all written as part of allotted time segments which may have a direct bearing on what the authors decide to include in their writing. Furthermore, due to the fact that students do not reference sources in these texts, it is unclear where the line should be drawn between their original contribution to the argument, and the ideas included in the referenced texts. Then, the category marked 'attitudinal' is unnecessarily vague, and does not indicate the precise nature of the evidentiality, whether it is certainty or doubt, which is relevant for formal writing in English (Biber and Finegan, 2016): it can indicate the difference between three styles of expository writing, a faceless style, an informational style presenting uncertain information requiring overt markers of doubt, and a 'challenged style' of assertions of questionable veracity, which requires overt markers of certainty.

In general, greater attention should be paid to the semantic features associated with stance taking in writing. Perhaps a separate study could focus on these markers in particular. In addition, a larger corpus of undergraduate students from other higher education institutions and with different L2 backgrounds and majors should further be analyzed. And finally, since the majority of the referenced studies focused on more advanced FL learners, it would be beneficial for further analysis to also focus on younger EFLs at lower levels of proficiency.

ACKNOWLEDGMENT: The second author gratefully acknowledges support from the Ministry of Education, Science and Technological Development of the Republic of Serbia (project grant 178014). 


\section{REFERENCES}

Bahrami, L., Dowlatabadi, H. R., Yazdani, H., Amerian, M. 2018. Authorial Stance in Academic Writing: Issues and Implications for Research in English Language Teaching. International Journal of English Language \& Translation Studies, 6(2), 69-80. DOI:10.1016/j.pragma.2008.09.010

Baratta, A. M. 2009. Revealing stance through passive voice. Journal of Pragmatics, 41(7), 1406-1421. https://doi.org/10.1016/j.pragma.2008.09.010

Baumgarten, N., House, J. 2010. I think and I don't know in English as lingua franca and native English discourse. Journal of Pragmatics, 42(5), 1184-1200. DOI:10.1016/j. pragma.2009.09.018

Biber, D., Finegan, E. 1989. Styles of Stance in English Lexical and Grammatical Marking of Evidentiality and Affect. Text, 9, 93-124. 10.1515/text.1.1989.9.1.93

Blagojević, S. 2009. Expressing attitudes in academic research articles written by English and Serbian authors. Facta Universitatis, Series: Linguistics and Literature, 7(1), 63-73.

Chandrasegaran, A. 2008. NNS students' arguments in English: Observations in formal and informal contexts. Journal of Second Language Writing, 17, 237-254. https://doi.org/10. 1016/j.jslw.2008.04.003

Chandrasegaran, A., Kong, K. M. C. 2006. Stance-taking and stance-support in students' online forum discussion. Linguistics and Education, 17(4), 374-390. doi:10.1016/j. linged.2007.01.003

Chang, L. 2009. Stance uses of the Mandarin LE constructions in conversational discourse. Journal of Pragmatics, 41(11), 2240-2256. DOI:10.1016/j.pragma.2008.06.003

Charles, M. 2007. Argument or evidence? Disciplinary variation in the use of the Noun that pattern in stance construction. English for Specific Purposes, 26, 203-218. DOI:10.1016/j.esp.2006.08.004

Englebretson, R. 2007. Stancetaking in discourse: subjectivity, evaluation, interaction. Amsterdam/Philadelphia: John Benjamins Publishing Company.

Filipović, J., Vučo, J., Đurić, Lj. 2007. Critical review of language education policies in compulsory primary and secondary education in Serbia. Current Issues in Language Planning, 8(1), 222-242. https://doi.org/10.2167/cilp103.0

Grigoriev, I., Sokolova, A. 2019. Corpus based analysis of first-person pronouns in research proposals written by Russian students. The Journal of Teaching English For Specific and Academic Purposes, 7(4), 423-430. https://doi.org/10.22190/JTESAP1904423G

Harmer, J. 2004. How to Teach Writing. Essex: Longman.

Hyland, K. 1998. Hedging in scientific research articles. Amsterdam: John Benjamins.

Hyland, K. 1999. Talking to students: Metadiscourse in introductory coursebooks. Journal of English for Specific Purposes, 18(1), 3-26. https://doi.org/10.1016/S0889-4906(97) 00025-2

Hyland, K. 2000. Disciplinary discourses: Social interactions in academic writing. London: Longman.

Hyland, K. 2005. Stance and engagement: a model of interaction in academic discourse, Discourse Studies, 7(2), 173-92. DOI:10.1177/1461445605050365

Hyland, K. 2012. Undergraduate Understandings: Stance and Voice in Final Year Reports. Hyland, K., Sancho Guinda C. (eds.) Stance and Voice in Written Academic Genres, 134150. Palgrave Macmillan.

Jaffe, A. (ed.) 2009. Stance: sociolinguistic perspectives. Oxford: Oxford University Press. 
Jiang, F. 2017. Stance and voice in academic writing: The "noun + that" construction and disciplinary variation. International Journal of Corpus Linguistics, 22(1), 85-106. https://doi.org/10.1075/ijcl.22.1.04jia

Kärkkäinen, E. 2003. Epistemic Stance in English Conversation: A description of its interactional functions, with a focus on I think. Amsterdam/Philadelphia: John Benjamins Publishing Company.

Lee, J., Deakin, L. 2016. Interaction in L1 and L2 undergraduate student writing: Interactional metadiscourse in successful and less successful argumentative essays. Journal of Second Language Writing, 33, 21-34. https://doi.org/10.1016/j.jslw.2016.06.004

Luchini, P. L. 2002. Evaluation of Teachers' Methodology of Writing Skill Teaching: A Case Study. The Linguistics Association of Korea Journal, 10(4), 211-232.

Man, D., Chau, M. H. 2019. Learning to evaluate through that-clauses: Evidence from a longitudinal learner corpus, Journal of English for Academic Purposes, 37, 22-33. https://doi.org/10.1016/j.jeap.2018.11.007

Min, S., Paek, J. K., Kang, Y. 2019. Exploring the use of hedges and stance devices in relation to Korean EFL learners' argumentative writing qualities. English Teaching, 74(1), 3-23. https://doi.org/10.15858/engtea.74.1.201903.3

Niemelä, M. 2010. The reporting space in conversational storytelling: Orchestrating all semiotic channels for taking a stance. Journal of Pragmatics, 42(12), 3258-3270. https://doi.org/10.1016/j.pragma.2010.06.015

Nunan, D. 1989. Designing Tasks for Communicative Classroom. Cambridge: Cambridge University Press.

Ragnarsdottir, H. Stromqvist, S. 2005. The development of generic maður/man for the construction of discourse stance in Icelandic and Swedish. Journal of Pragmatics, 37(2), 143-155. https://doi.org/10.1016/j.pragma.2004.08.007

Reilly, J., Zamoraa, A., McGiverna, R. F. 2005. Acquiring perspective in English: the development of stance. Journal of Pragmatics, 37, 185-208. https://doi.org/10.1016/ j.pragma.2004.08.010

Ryshina-Pankova, M. 2011. Developmental changes in the use of interactional resources: Persuading the reader in FL book reviews. Journal of Second Language Writing, 20, 243256. https://doi.org/10.1016/j.jslw.2011.05.011

Silver, M. 2003. The stance of stance: a critical look at ways stance is expressed and modeled in academic discourse. Journal of English for Academic Purposes, 2, 359-374. https://doi.org/10.1016/S1475-1585(03)00051-1

Swales, J. M. 1990. Genre analysis: English in academic and research settings. Cambridge: Cambridge University Press.

van Hell, Janet. G., Verhoeven, L., Tak, M., van Oosterhout, M. 2005. To take a stance: a developmental study of the use of pronouns and passives in spoken and written narrative and expository texts in Dutch. Journal of Pragmatics, 37(2), 239-273. https://doi.org/ 10.1016/j.pragma.2004.08.004

Vincent, D., Perrin, L. 1999. On the narrative vs non-narrative functions of reported speech: A socio-pragmatic study. Journal of Sociolinguistics, 3(3), 291-313. [Google Scholar] 